\title{
Análise da progressão do equilíbrio em diferentes subtipos de migrânea
}

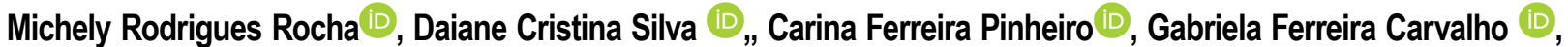 \\ Fabíola Dach ${ }^{(1)}$, Débora Bevilaqua-Grossi $\mathbb{D}$
}

Faculdade de Medicina de Ribeirão Preto, Universidade de São Paulo, Ribeirão Preto São Paulo, Brasil.

\begin{abstract}
Introdução
A migrânea é comumente associada a déficits de equilíbrio, que progridem mais rapidamente do que em indivíduos sem cefaleia. Porém, ainda não está definido se a progressão é mais evidente na presença de aura ou em pacientes com migrânea crônica.
\end{abstract}

\section{Objetivo}

Analisar as alterações no equilíbrio de pacientes com migrânea com e sem aura, e migrânea crônica, após um ano.

\section{Métodos}

Estudo longitudinal prospectivo, em que foram avaliadas 105 mulheres, sendo 26 voluntárias sem cefaleia (GC;31,8 8 9.9 anos), 27 com migrânea sem aura (MSA;31,9 \pm 8.4 anos), 25 com migrânea com aura (MA;32,6 68.8 anos) e 27

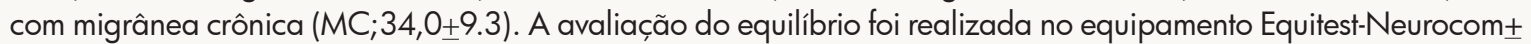
através do teste de organização sensorial (TOS). Todas as participantes foram reavaliadas após um ano. Aprovação do comitê de ética e pesquisa: CAAE 04683218.3.0000.5440.

\section{Resultados}

A comparação entre as variáveis foi feita em cada um dos grupos com ANOVA medidas repetidas, com o tempo o fator de repetição $(p<0,05)$. As diferenças médias são apresentadas. Após um ano, houve redução da frequência da migrânea nos grupos $M A(-2,20 ; p=0,01)$ e $M C(-10,8 ; p<0,001)$ e redução da intensidade da migrânea no grupo $M C(-2,26 ; p=0,001)$. Não foram observadas diferenças significativas após um ano em nenhum dos grupos no escore de equilíbrio final do TOS (CG 0,03; $p=0,95 ;$ MsA 1,40; $p=0,26, M A 3,04 ; p=0,38, M C 2,74 ; p=0,06$ ) e nem nos scores de equilíbrio referentes aos sistemas somatossensorial (CG 0,61; $p=0,25, \mathrm{MsA} 1,40 ; p=0,07, \mathrm{MA}$ 2,16; $p=0,13, M C 1,14 ; p=0,28$ ), visual (CG 2,42; $p=0,06$, MsA 0,37; $p=0,89$, MA 3,04; $p=0,38, M C$ 3,33; $p=0,27$ ) e vestibular (CG -1,15; $p=0,46, M s A-0,22 ; p=0,92, M A-1,12 ; p=0,80, M C 3,37 ; p=0,22$ ).

\section{Conclusão}

Os déficits de equilíbrio observados nos subtipos de migrânea não apresentam mudança após o intervalo de um ano. No entanto, foi observada melhora na frequência e intensidade das crises.

Palavras-chave: Cefaleia, Equilíbrio, Posturografia computadorizada dinâmica 